\title{
MicroRNA-146a inhibits the inflammatory responses induced by interleukin-17A during the infection of Helicobacter pylori
}

\author{
NA LI ${ }^{1,2}$, JIANLONG WANG $^{3}$, WENQIAN YU ${ }^{1}$, KAI DONG $^{1}$, FENG YOU $^{1}$, BIAO SI $^{1}$, \\ BIN TANG ${ }^{2}$, YAN ZHANG ${ }^{1}$, TONGJIAN WANG ${ }^{1}$ and BIN QIAO ${ }^{1}$ \\ ${ }^{1}$ Institute of Cardiovascular Disease, The 960th Hospital of Chinese PLA, Jinan, Shandong 250022; \\ ${ }^{2}$ Department of Clinical Microbiology and Immunology, Southwest Hospital and College of Medical Laboratory Science, \\ The Third Military Medical University, Chongqing, Sichuan 400038; ${ }^{3}$ Department of Pediatrics, \\ The First People's Hospital of Jining, Jining, Shandong 272000, P.R. China
}

Received March 21, 2018; Accepted November 14, 2018

DOI: $10.3892 / \mathrm{mmr} .2018 .9725$

\begin{abstract}
Helicobacter pylori (H. pylori) infection is the major cause of chronic active gastritis and peptic ulcer disease. Upregulation of IL-17A is associated with H. pylori infection in the gastric mucosa; however, the factors involved in the regulation of interleukin (IL)-17A-induced inflammatory responses in $H$. pylori-associated gastritis remain unknown. MicroRNAs (miRNAs) serve as key post-transcriptional regulators of gene expression and are associated with the $H$. pylori infection. The present study aimed to analyze the effects of IL-17A on the expression of miR-146a upon infection with $H$. pylori, as well as to identify the possible impact of miR-146a dysregulation on the inflammatory response in vivo and in vitro. Reverse transcription-quantitative polymerase chain reaction analysis was used to determine the expression levels of miR-146a in gastric epithelial cells upon IL-17A stimulation. The effects of miR-146a mimics on IL-17A-induced inflammatory responses in SGC-7901 cells were evaluated. The effects of miR-146a mimics on the expression levels of IL-1 receptor-associated kinase 1 (IRAK1) and tumor necrosis factor receptor-associated factor 6 (TRAF6) upon IL-17A treatment were analyzed, and the IL-17A-stimulated inflammation following the silencing of IRAK1 and TRAF6 was observed. In addition, the correlation between miR-146a and IL-17A in human gastric mucosa with $H$. pylori was
\end{abstract}

Correspondence to: Dr Tongjian Wang or Dr Yan Zhang, Institute of Cardiovascular Disease, The 960th Hospital of Chinese PLA, 8 Lashan Road, Jinan, Shandong 250022, P.R. China

E-mail: wangtongjian0425@126.com

E-mail: zhangyan90zy@163.com

Abbreviations: H. pylori, Helicobacter pylori; IL-17A, interleukin-17A; IL-8, interleukin-8; GRO- $\alpha$, growth-regulated oncogene $\alpha$; IRAK1, interleukin-1 receptor-associated kinase 1; TRAF6, tumor necrosis factor receptor-associated factor 6

Key words: helicobacter pylori, interleukin-17A, microRNA-146a, inflammation, interleukin-8, growth-regulated oncogene- $\alpha$ examined. The results indicated that IL-17A-induced miR-146a may regulate the inflammatory response during the infection of $H$. pylori in a nuclear factor- $\kappa \mathrm{B}$-dependent manner. Furthermore, the expression of miR-146a and IL-17A are positively correlated in human gastric mucosa infected with $H$. pylori. These data suggested that miR-146a may serve as a biomarker or therapeutic target in gastritis therapy.

\section{Introduction}

Helicobacter pylori (H. pylori) is a spiral-shaped gram-negative bacterium that can be selectively planted in the human stomach, resulting in various gastric diseases, including gastritis, gastric adenocarcinoma, peptic ulcer disease and gastric mucosa-associated lymphoma $(1,2)$. H. Pylori promotes the production of various types of cytokines in gastric mucosa, which leads to chronic inflammation and epithelial cell damage.

Previous studies indicated that excessive production of interleukin (IL)-17A was associated with a variety of inflammatory diseases, including experimental autoimmune encephalomyelitis (3), extrinsic allergic alveolitis (4), inflammatory bowel diseases (5), collagen-induced arthritis (6) and psoriasis (7). IL-17A belongs to the IL-17 family, which are produced by cluster of differentiation (CD) $4^{+}$Th17 cells and other subsets of immune cells (8). IL-17A induces the production of cytokines and chemokines, including IL-8 and growth-regulated oncogene $\alpha(\mathrm{GRO}-\alpha)$ in epithelial cells and macrophages, and exhibits a pro-inflammatory effects (9). In addition, upregulation of IL-17A is associated with H. pylori infection in the gastric mucosa $(10,11)$. IL-17A also stimulates gastric mononuclear and epithelial cells to produce IL-8, suggesting that IL-17A serves an important role in $H$. pylori-induced inflammation $(10,12)$; however, the factors that participate in IL-17A-mediated inflammatory responses in $H$. pylori-associated gastritis remain unknown.

MicroRNAs (miRNAs/miRs) serve biological functions in the immune system (13-15). Aberrant expression of miRNAs, such as miR-146a, is associated with numerous inflammatory disorders (16), and is enhanced by the stimulation with inflammatory cytokines (17). For example, 
miR-146a was upregulated by IL-1 $\beta$ and Toll-like receptors (TLRs), such as TLR2 $(18,19)$. Previous studies have indicated that miR-146a was upregulated following $H$. pylor $i$ infection in a nuclear factor- $\kappa \mathrm{B}(\mathrm{NF}-\kappa \mathrm{B})$-dependent manner (20-22). In addition, miR-146a overexpression regulates inflammation responses by inhibiting its target genes, including tumor necrosis factor (TNF) receptor-associated factor 6 (TRAF6) and IL-1 receptor-associated kinase 1 (IRAK1) $(23,24)$. TRAF6 and IRAK1 function as signal transducers in the NF- $\kappa \mathrm{B}$ pathway that activates $i \kappa \mathrm{B}$ kinase in response to proinflammatory cytokines $(23)$. NF- $\kappa \mathrm{B}$ is an essential signaling factor involved in the progression of H. pylori infection (25). It has been reported that miR-146a could inhibit TRAF6- and IRAK1-mediated signaling by acting as a negative regulator in the inflammatory state (26); however, whether miR-146a suppresses inflammatory responses by stimulating IL-17A during $H$. pylori infection remains unknown.

In the present study, the expression of miR-146a was increased by IL-17A stimulation in gastric epithelial cells; whether the induction of miR-146a affects the activities of IL-17A induced inflammatory responses in H. pylori-associated gastritis was investigated. In addition, the correlation of IL-17A and miR-146a expression in $H$. pylori-infected gastric tissues was evaluated.

\section{Materials and methods}

Cell culture and H. pylori strain. A human gastric cancer cell line, SGC-7901 was purchased from the cell bank of Shanghai Institutes for Biological Sciences, Chinese Academy of Sciences (Shanghai, China). The cells were routinely cultured in RPMI-1640 medium purchased from Gibco supplemented with 10\% FBS (both Thermo Fisher Scientific, Inc., Waltham, MA, USA) at $37^{\circ} \mathrm{C}$ in a humidified atmosphere of $5 \% \mathrm{CO}_{2}$. H. pylori strain 26695 was obtained from the American Type Culture Collection (Manassas, VA, USA) and cultured in brain-heart infusion agar (BHI; Becton, Dickinson and Company, Franklin Lakes, NJ, USA) plates with 10\% rabbit blood (cat. no. HQ50073; Shanghai Bangsheng Biotechnology Co., Ltd., Shanghai, China) at $37^{\circ} \mathrm{C}$ under the microaerophilic conditions of $5 \% \mathrm{O}_{2}$, $10 \% \mathrm{CO}_{2}$ and $85 \% \mathrm{~N}_{2}$.

Infection of SGC-7901 cells with H. pylori 26695. H. pylori was collected from the culture plates using $2 \mathrm{ml}$ sterile PBS followed by centrifugation at $2500 \mathrm{x} \mathrm{g}$ for $5 \mathrm{~min}$ at room temperature, and resuspended in RPMI-1640 medium. The concentration of $H$. pylori 26695 was determined at $600 \mathrm{~nm}$ using the Agilent 8453E UV-visible Spectroscopy System (Agilent Technologies, Inc., Santa Clara, CA, USA): Optical density $(600 \mathrm{~nm})=1 \times 10^{9}$ colony forming unit $/ \mathrm{ml}$. SGC-7901 cells were infected with $H$. pylori 26695 for $6 \mathrm{~h}$ at $37^{\circ} \mathrm{C}$, with the multiplicity of infection 100 .

Cytokine measurements by ELISA. An ELISA was employed to evaluate the inflammatory response of SGC-7901 cells subjected to IL-17A stimulation at serial concentrations $(0,0.01,0.1,1$ or $10 \mathrm{ng} / \mathrm{ml})$ over $24 \mathrm{~h}$ at $37^{\circ} \mathrm{C}$, or treated with $10 \mathrm{ng} / \mathrm{ml} \mathrm{IL}-17 \mathrm{~A}$ at different time points $(0,6,12,18$ or $24 \mathrm{~h})$ at $37^{\circ} \mathrm{C}$. Cell culture supernatants were collected by centrifugation at $1,000 \mathrm{x} \mathrm{g}$ for $20 \mathrm{~min}$ at room temperature, and the expression levels of IL-17A (cat. no. D1700), GRO- $\alpha$ (cat. no. DGR00B) and IL-8 (cat. no. D8000C) in the supernatant were determined using DuoSet ELISA Development System (R\&D Systems, Minneapolis, MN, USA) according to the manufacturer's protocols. Absorbance at $450 \mathrm{~nm}$ was detected using a microplate reader.

Analysis of miR-146a and mRNA by reverse transcription-quantitative polymerase chain reaction ( $R T$-qPCR). Total RNA was extracted from tissues or cells using TRIzol ${ }^{\circledR}$ reagent (Invitrogen; Thermo Fisher Scientific, Inc.) according to the manufacturer's instructions. For RT-qPCR analysis of miR-146a, the total RNA isolated from cells was reverse transcribed to cDNA using a TaqMan MicroRNA Reverse Transcription Kit (Applied Biosystems; Thermo Fisher Scientific, Inc.) The reactions were incubated at $16^{\circ} \mathrm{C}$ for $30 \mathrm{~min}$, followed by $42^{\circ} \mathrm{C}$ for $30 \mathrm{~min}$, then $85^{\circ} \mathrm{C}$ for $5 \mathrm{~min}$ before being held at $4^{\circ} \mathrm{C}$. The expression levels of miR-146a were evaluated using TaqMan miRNA assays (Ambion; Thermo Fisher Scientific, Inc.) according to the manufacturer's protocols. The reactions were performed using a Bio-Rad IQ5 (Bio-Rad Laboratories, Inc., Hercules, CA, USA) with the following program: $95^{\circ} \mathrm{C}$ for $2 \mathrm{~min}, 40$ cycles of $95^{\circ} \mathrm{C}$ for $15 \mathrm{sec}$ and $60^{\circ} \mathrm{C}$ for $30 \mathrm{sec}$. U6 was used as internal reference. The upstream and downstream primers of miR-146a and U6 were synthesized by Sangon Biotech Co., Ltd. (Shanghai, China) and the sequences were as follows: miR-146a forward, 5'-GTGCAGGGTCCGAGGT-3' and reverse, 5'-CGGCGGTGAGAACTGAATTCC-3'; U6 forward, 5'-CTCGCTTCGGCAGCACA-3' and reverse, 5'-AACGCT TCACGAATTTGCGT-3'. Relative expression of miR-146a was analyzed using $2^{-\Delta \Delta C q}$ method (27). The results were repeated at least three times.

The expression levels of IL-17A were determined using a PrimeScript RT-PCR kit (Takara Bio, Inc., Otsu, Japan). The expression was normalized using $\beta$-actin. The primer sequences are as follows: IL-17A forward, 5'-AGGAATCAC AATCCCACGAA-3' and reverse, 5'-ACTTTGCCTCCCAGA TCACA-3'; $\beta$-actin forward, 5'-TTCCTTCCTGGGCATGGA GTCC-3' and reverse, 5'-TGGCGTACAGGTCTTTGCGG-3'.

Oligonucleotide transfection. All oligonucleotides were obtained from Shanghai GenePharma Co., Ltd. (Shanghai, China) and transfected into SGC-7901 cells using Lipofectamine ${ }^{\circledR} 2000$ (Invitrogen; Thermo Fisher Scientific, Inc.). Briefly, SGC-7901 cells were seeded in 6-well plates at a concentration of $2.0 \times 10^{5}$ cells/well in RPMI-1640 supplemented with $10 \% \mathrm{FBS}$. After subculturing at $37^{\circ} \mathrm{C}$ for $24 \mathrm{~h}$ under $5 \% \mathrm{CO}_{2}$, the medium was replaced with fresh serum-free medium purchased from Gibco (Opti-MEM ${ }^{\circledR} \mathrm{I}$ Reduced Serum Medium; Thermo Fisher Scientific, Inc.), and SGC-7901 cells were transfected with miR-146a mimics (50 nM; 5'-UGAGA ACUGAAU UCCAUGGGUU-3'; 5'-CCCAUGGAAUUCAGUUCUCAUU-3'), scrambled miR control (50 nM; forward, 5'-UUCUCCGAACGU GUCACGUTT-3' and reverse, 5'-ACGUGACACGUUCGG AGAATT-3'), IRAK1 small interfering (si)RNA (100 nM; forward, 5'-GGUUUCGUCACCCAAACAUtt-3' and 
reverse, 5'-AUGUUUGGGUGACGAAACCtg-3') or TRAF6 siRNA (100 nM; forward, 5'-GGUUGUUUGCACAAGAUG Gtt-3' and reverse, 5'-CCAUCUUGUGCAAACAACCtt-3'). The mock treatment group was transfected with transfection reagent only. FAM-labeled negative control siRNA (100 nM) purchased from Ambion (cat. no. AM4620; Thermo Fisher Scientific, Inc.) was transfected into SGC-7901 cells to evaluate the transfection efficiency; $>80 \%$ of the cells were successfully transfected (data not shown). After transfection for $24 \mathrm{~h}$, the cells were treated with $10 \mathrm{ng} / \mathrm{ml} \mathrm{IL-17A} \mathrm{(cat.}$ no. 200-17; Peprotech, Inc., Rocky Hill, NJ, USA) for 24 h.

Western blotting. Western blot analysis was performed as previously described (28). The blot was probed with primary antibodies at $4^{\circ} \mathrm{C}$ overnight: Anti-IRAK1 (1:1,000; cat. no. 4362) and anti-TRAF6 (1:1,000; cat. no. 4743), were used to determine the expression levels of IRAK1 and TRAF6, respectively; Anti- $\beta$-actin (1:1,000; cat. no. 5125; all Cell Signaling Technology, Inc., Danvers, MA, USA) was used as an internal control. Next, membranes were incubated with horseradish peroxidase-conjugated secondary antibodies, goat-anti-mouse (1:5,000; cat. no. 115-035-003) or goat-anti-rabbit (1:5,000; cat. no. 111-035-003; both Jackson ImmunoResearch Laboratories., Inc., West Grove, PA, USA) at $37^{\circ} \mathrm{C}$ for $2 \mathrm{~h}$. Protein bands were visualized using SuperSignal West Dura Duration substrate reagent (cat. no. 34080; Thermo Fisher Scientific, Inc.). Blots were quantified using Image J software (version 1.48; National Institutes of Health, Bethesda, MD, USA).

Evaluation of NF- $\kappa \mathrm{B}$ activity. For NF- $\kappa \mathrm{B}$ activity analysis, SCG-7901 cells were co-transfected with $0.8 \mathrm{mg}$ of the reported luciferase vector pNF-kB-TA-Luc (cat. no. 631904; Clontech Laboratories, Inc., Mountainview, CA, USA), 0.04 mg of Renilla control vector (pRL-TK; cat. no. 2241; Promega Corporation, Madison, WI, USA) and miR-control/miR-146a mimics by using Lipofectamine 2000 according to the manufacturer's protocols. After $24 \mathrm{~h}$, the cells were stimulated with or without $10 \mathrm{ng} / \mathrm{ml} \mathrm{IL-17A}$ (cat. no. 200-17; Peprotech, Inc.) for $12 \mathrm{~h}$ at $37^{\circ} \mathrm{C}$. Luciferase activity was analyzed using the Dual-Luciferase Reporter Assay System (Promega Corporation). Firefly luciferase activity was normalized to that of Renilla luciferase.

Patient samples. In total, 40 samples from were collected from patients with gastric mucosa (18 women and 22 men, 25-60-years-old) who underwent endoscopy due to dyspeptic symptoms at Southwest Hospital (Chongqing, China) between January 2013 and December 2014, including 20 patients with $H$. pylori-induced chronic gastritis and 20 healthy donors. None of the patients had been administered nonsteroidal anti-inflammatory drugs, antibiotics or proton pump inhibitor drugs. Identification of $H$. pylori infection in gastric mucosa was performed via $H$. pylori culture, $\mathrm{C} 13$-urea breath tests and histological analysis. The present study was approved by the Ethics Committee of the Institutional Review Board at The Third Military Medical University (Chongqing, China), and written informed consent was obtained from all patients.

Statistical analyses. Data were presented as the mean \pm standard deviation of at least three independent experiments. Data were analyzed using a Student's t-test or analysis of variance followed by a Dunnett's post-hoc test. The association between the expression levels of miR-146a and IL-17A was analyzed using Pearson's correlation. All statistical analyses were performed using GraphPad Prism software (GraphPad Software, Inc., La Jolla, CA, USA). P $<0.05$ was considered to indicate a statistically significant difference.

\section{Results}

IL-17A enhances the production of GRO- $\alpha$ and IL-8 in SGC-7901 cells. Previous studies reported that $H$. pylori infection may stimulate the secretion of IL-17A $(10,11,29)$, which was also confirmed in human gastric cancer cell line SGC-7901 in the present study. As presented in Fig. 1A, $H$. pylori infection significantly increased the protein levels of IL-17A in SGC-7901 cells compared with the control. Furthermore, to investigate the roles of IL-17A in inflammation, the expression levels of GRO- $\alpha$ and IL-8 were examined by ELISA. As presented in Fig. 1B, production of GRO- $\alpha$ and IL-8 were significantly increased in SGC-7901 cells following treatment with $0.01-10 \mathrm{ng} / \mathrm{ml} \mathrm{IL}-17 \mathrm{~A}$ over $24 \mathrm{~h}$ compared with the control. The expression levels of GRO- $\alpha$ and IL-8 in SGC-7901 cells were also significantly increased in a time-dependent manner (Fig. 1C). These data indicated that $H$. pylori-associated production of IL-17A could upregulate GRO- $\alpha$ and IL-8 in gastric epithelial cells, suggesting a potential role of IL-17A in $H$. pylori-induced inflammation.

miR-146a is upregulated in SGC-7901 cells upon IL-17A stimulation. Previous studies have revealed that the expression levels of miR-146a was significantly increased in gastric epithelial cells following the stimulation by H. pylori $(20,30)$. Whether $H$. pylori-induced IL-17A can enhance the expression of miR-146a in SGC-7901 cells was further investigated in the present study. As presented in Fig. 2A, the expression levels of miR-146a were significantly increased in SGC-7901 cells treated with 1 and $10 \mathrm{ng} / \mathrm{ml}$ IL-17A over $12 \mathrm{~h}$ compared with the control; but no significant difference was observed in SGC-7901 cells treated with 0.01 or $0.1 \mathrm{ng} / \mathrm{ml} \mathrm{IL-17A.}$ In addition, the expression of miR-146a was significantly upregulated from $6-24 \mathrm{~h}$ following treatment with $10 \mathrm{ng} / \mathrm{ml}$ IL-17A compared with the control; expression peaked at $12 \mathrm{~h}$ and reduced thereafter (Fig. 2B). These results suggested that miR-146a expression is increased in gastric epithelial cells upon the stimulation with IL-17A.

miR-146a downregulates IRAK1 and TRAF6, which are involved in IL-17A-mediated inflammation in vitro. A previous study indicated that IL-17A induced the production of proinflammatory cytokines via the NF- $\mathrm{kB}$ signaling pathway (31). Thus, whether miR-146a regulated proinflammatory cytokines in a NF- $\mathrm{kB}$-dependent manner was investigated. As presented in Fig. 3A, luciferase report assays revealed that miR-146a mimics significantly inhibited the activity of NF- $\mathrm{KB}$ compared with the control. Furthermore, IRAK1 and TRAF6 have been reported as two potential targets of miR-146a, and are involved in the activation of NF- $\mathrm{KB}$ (30). In the present study, miR-146a significantly reduced the 

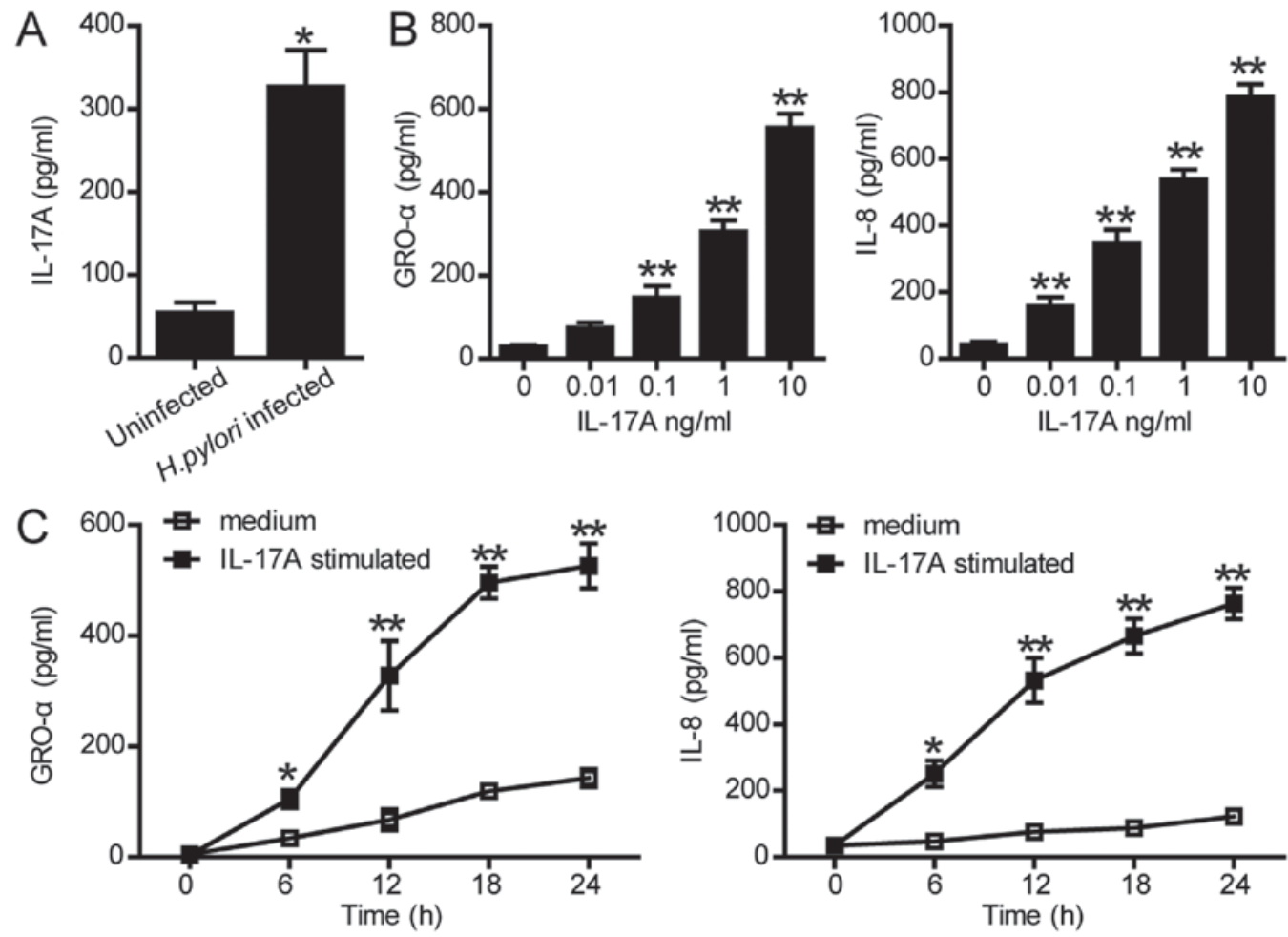

Figure 1. IL-17A stimulates the production of GRO- $\alpha$ and IL-8 in SGC-7901 cells. (A) Expression levels of IL-17A were determined in SGC-7901 cells following Helicobacter pylori infection for $24 \mathrm{~h}$ (multiplicity of infection=100). " $\mathrm{P}<0.05$, vs. uninfected cells. (B) Protein levels of GRO- $\alpha$ and IL-8 in cells treated with serial concentrations of IL-17A for $24 \mathrm{~h}$ were evaluated by ELISA ${ }^{* *} \mathrm{P}<0.01$, vs. $0 \mathrm{ng} / \mathrm{ml}$ IL-17A. (C) Quantification of the protein levels of GRO- $\alpha$ and IL- 8 in cells treated with $10 \mathrm{ng} / \mathrm{ml}$ IL-17A at different time points. ${ }^{*} \mathrm{P}<0.05$ and ${ }^{* *} \mathrm{P}<0.01$, vs. the control group. IL-17A, interleukin-17A; GRO- $\alpha$, growth-regulated oncogene $\alpha$; IL-8, interleukin-8.
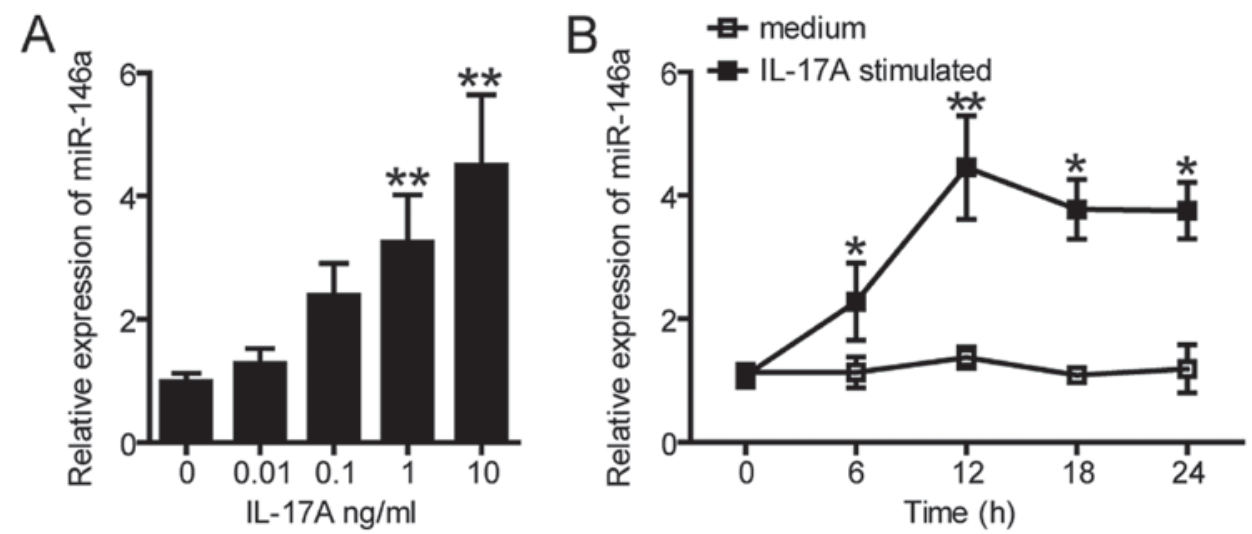

Figure 2. Effects of IL-17A stimulation on the expression of miR-146a in SGC-7901 cells. (A) Expression levels of miR-146a were evaluated by reverse transcription-quantitative polymerase chain reaction in SGC-7901 cells treated with serial concentrations of IL-17A for $12 \mathrm{~h}$. " ${ }^{* *} \mathrm{P}<0.01$, vs. $0 \mathrm{ng} / \mathrm{ml} \mathrm{IL}-17 \mathrm{~A}$. (B) Expression levels of miR-146a were determined in SGC-7901 cells treated with $10 \mathrm{ng} / \mathrm{ml}$ IL-17A over the indicated time points. "P<0.05 and ${ }^{* *} \mathrm{P}<0.01$ vs. the control group. IL-17A, interleukin-17A; miR, microRNA.

protein expression of IRAK1 and TRAF6 upon stimulation with IL-17A (Fig. 3B). To further determine the biological functions of IRAK1 and TRAF6 on IL-17A-stimulated inflammatory responses, specific siRNAs were used to inhibit the expression of IRAK1 and TRAF6 (Fig. 3C). Western blot analysis revealed that downregulation of IRAK1 and TRAF6 significantly decreased the protein levels of GRO- $\alpha$ and IL-8 compared with the control (Fig. 3D), which suggested that IL-17A-induced expression of miR-146a may suppress the expression of IRAK1 and TRAF6, attenuating NF- $\kappa$ B activity and affecting inflammation.
Overexpression of miR-146a suppresses IL-17A-induced inflammatory responses in SGC-7901 cells. Previous studies revealed that miR-146a participated in the negative feedback regulation of inflammation during $H$. pylori infection (20-22,30); thus the effects of miR-146a on IL-17A-induced inflammatory responses in SGC-7901 cells were investigated. The expression levels of miR-146a in transfected SGC-7901 cells were determined using RT-qPCR (Fig. 4A). As presented in Fig. 4B, SGC-7901 cells were transfected with miR control or miR-146a mimics followed by treatment with IL-17A. As presented in Fig. 4B, miR-146a mimics significantly decreased 


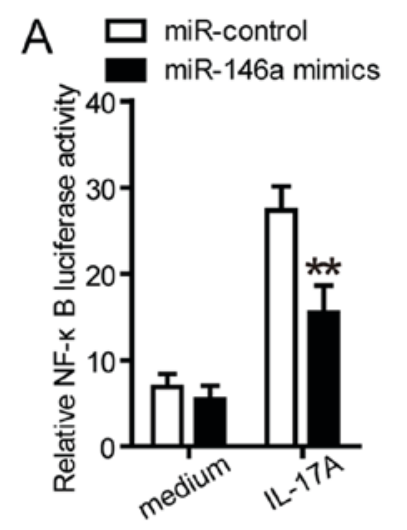

B


D
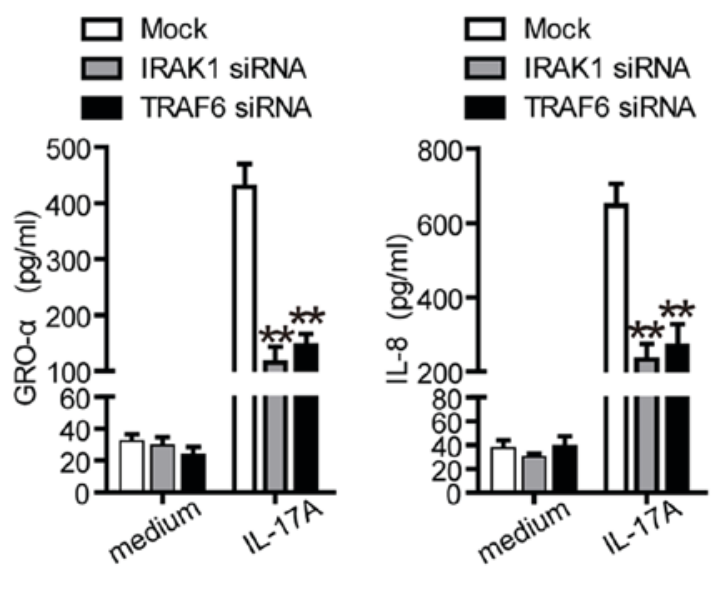

Figure 3. IRAK1 and TRAF6 are downregulated by miR-146a and are involved in IL-17A-stimulated inflammation in vitro. (A) SGC-7901 cells were co-transfected with the reporter luciferase vector pNF-kB-TA-Luc, and miR-control or miR-146a mimics for $24 \mathrm{~h}$ and treated with $10 \mathrm{ng} / \mathrm{ml} \mathrm{IL}-17 \mathrm{~A}$ for $12 \mathrm{~h}$. Cells were analyzed using a luciferase reporter assay. (B) Expression levels of IRAK1 and TRAF6 in SGC-7901 cells transfected with scrambled miR-control or miR-146a mimics at $100 \mathrm{nM}$ for $24 \mathrm{~h}$ followed by IL-17A stimulation $(10 \mathrm{ng} / \mathrm{ml})$ for $12 \mathrm{~h}$. (C) SGC-7901 cells were transfected with siRNA targeting IRAK1 or TRAF6 for $48 \mathrm{~h}$. The protein levels of IRAK1 and TRAF6 were determined by western blot analysis. (D) SGC-7901 cells were transfected with siRNA targeting IRAK1 or TRAF6 for $24 \mathrm{~h}$ followed by IL-17A stimulation (10 ng/ml) for $24 \mathrm{~h}$. The protein expression levels of GRO- $\alpha$ and IL-8 were evaluated. ${ }^{* *} \mathrm{P}<0.01$, vs. miR-control or Mock. GRO- $\alpha$, growth-regulated oncogene $\alpha$; IL-17A, interleukin-17A; IRAK1,

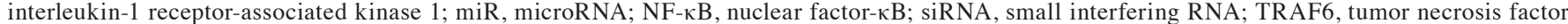
receptor-associated factor 6.
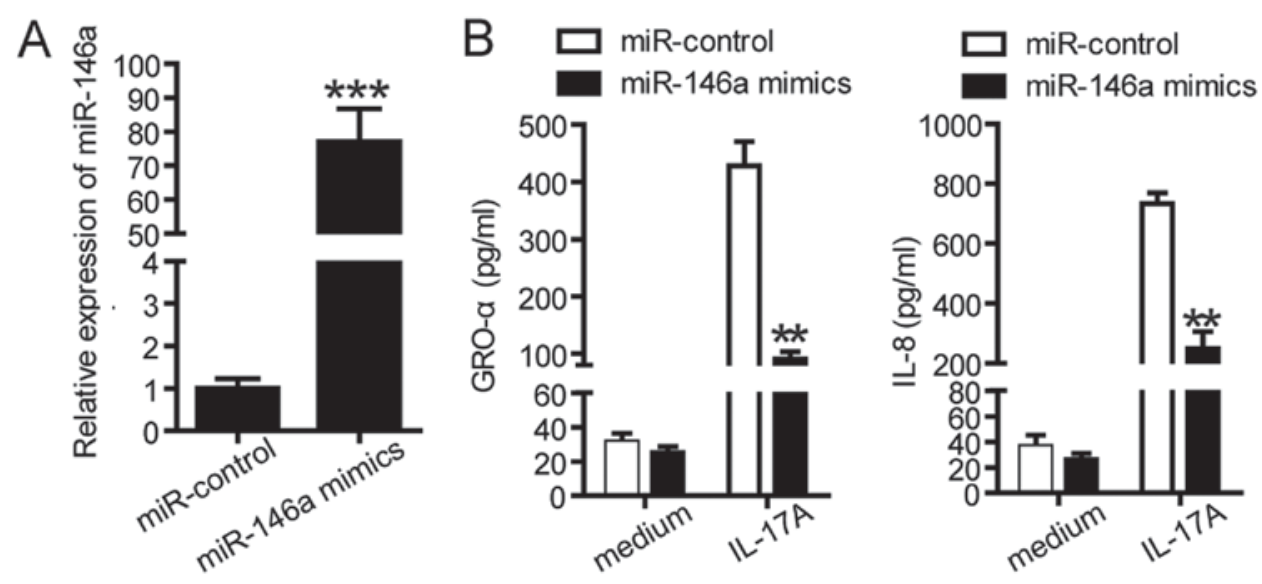

Figure 4. Overexpression of miR-146a suppresses IL-17A-induced inflammatory responses in SGC-7901 cells. (A) Expression levels of miR-146a were determined by reverse transcription-quantitative polymerase chain reaction following the transfection of miR-146a mimics or miR-control at $100 \mathrm{nM}$ for $24 \mathrm{~h}{ }^{* * * *} \mathrm{P}<0.001$, vs. miR-control. (B) Transfected cells with the indicated oligonucleotides at $100 \mathrm{nM}$ for $24 \mathrm{~h}$ followed by stimulation of IL-17A. The protein levels of GRO- $\alpha$ and IL-8 were evaluated. ${ }^{* *} \mathrm{P}<0.01$, vs. IL-17A-treated miR-control. GRO- $\alpha$, growth-regulated oncogene $\alpha$; miR, microRNA; IL-17A, interleukin-17A. 

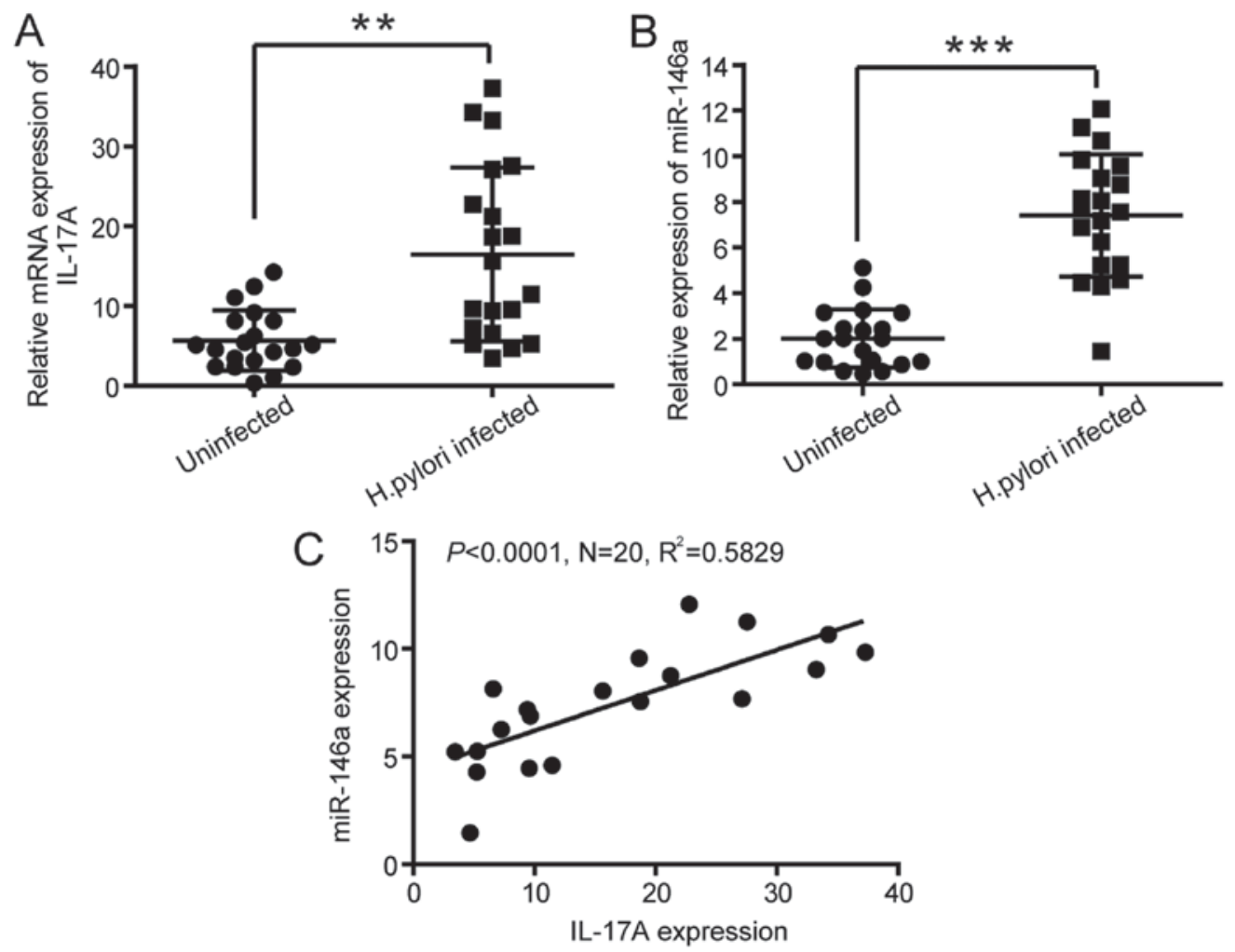

Figure 5. Correlation of the expression levels of IL-17A and miR-146a in human gastric mucosa infected with $H$. pylori. (A) and (B) Reverse transcription-quantitative polymerase chain reaction analysis of IL-17A and miR-146a mRNA in gastric mucosa tissues with $H$. pylori-induced chronic gastritis ( $\mathrm{n}=20$ ) and healthy controls $(\mathrm{n}=20){ }^{* *} \mathrm{P}<0.01$ and ${ }^{* * *} \mathrm{P}<0.001$, uninfected gastric mucosa $(\mathrm{C})$ A significant positive correlation between the expression levels of IL-17A and miR-146a was revealed $\left(\mathrm{R}^{2}=0.5829, \mathrm{P}<0.0001\right)$. H. pylori, Helicobacter pylori; IL-17A, interleukin-17A; miR, microRNA.

the protein levels of GRO- $\alpha$ and IL- 8 compare with the control. In summary, these data suggested that miR-146a serves a potential role in IL-17A-induced inflammatory responses.

Correlation between the expression of IL-17A and miR-146a in human gastric mucosa infected with H. pylori. To determine whether the expression levels of IL-17A were increased in $H$. pylori-infected gastric mucosa in vivo, the mRNA expression of IL-17A in gastric mucosa tissues from patients with $H$. pylori infection was determined. The mRNA levels of miR-146a and IL-17A were evaluated in gastric mucosa tissues from 20 patients with $H$. pylori-induced chronic gastritis and 20 healthy donors. The results of RT-qPCR revealed that the expression levels of IL-17A and miR-146a (Fig. 5A and B) were upregulated in $H$. pylori-infected gastric mucosa tissues compared with the normal tissues. Furthermore, Pearson's correlation analysis indicated a positive correlation between the mRNA levels of miR-146a and IL-17A $\left(\mathrm{R}^{2}=0.5829, \mathrm{P}<0.0001\right.$; Fig. 5C), suggesting that miR-146a is correlated with the production of IL-17A in H. pylori-infected human gastric mucosa.

\section{Discussion}

In the present study, the results revealed that: i) $H$. pylori infection in gastric mucosa stimulated the production of IL-17A, resulting in the synthesis of GRO- $\alpha$ and IL-8; ii) IL-17A induced the expression of miR-146a in gastric epithelial cells; iii) overexpression of miR-146a suppressed IL-17A-induced inflammatory responses in SGC-7901 cells; iv) miR-146a downregulated the expression of IRAK1 and TRAF6, which were involved in IL-17A-mediated inflammation in vitro; and vi) the expression levels of miR-146a were correlated with the production of IL-17A in $H$. pylori-infected human gastric mucosa. In summary, these findings suggested that IL-17A-induced miR-146a may function as a negative regulator on inflammation response in gastric mucosa during the infection of $H$. pylori.

The persistent infection of $H$.pylori may cause severe diseases including peptic ulcers and gastric carcinoma (32). Previous studies have reported that $H$. pylori infection can stimulate the production of IL-17A in the stomachs of human and mice $(11,33)$. In addition, the results of the present study indicated that the mRNA levels of IL-17A were increased in $H$. pylori-infected patients compared with the normal controls. IL-17A may be responsible for mucosal damage in $H$. pylori-induced gastritis $(34,35)$; these findings together with the present study have demonstrated that IL-17A served a role in the regulation of GRO- $\alpha$ and IL-8, which are the proinflammatory cytokines associated $H$. pylori infection. It has been reported that IL-17 $17^{-/}$ mice exhibited suppressed inflammatory responses and reduced $H$. pylori colonization in gastric mucosa (36), suggesting that IL-17A serves an important roles in inflammatory responses and host defense during the infection of $H$. pylori.

In the last decade, numerous studies focused on the role of miRNAs in immune responses. A previous study suggested that miRNAs contributed to the pathogenesis of immune disorders involved in Th17-mediated responses (37). A recent study indicated that $\mathrm{CD}^{+} \mathrm{T}$ cells transduced with miR-301a increased the levels of IL-17A and TNF- $\alpha$ in inflammatory bowel 
disease (38). In addition, miR-146a may regulate the production of IL-17 in the peripheral blood mononuclear cell and synovium in patients with rheumatoid arthritis (39). Liu et al (40) reported that IL-17 affected the expression of miRNA in brain astrocytes, such as miR-873, which regulates inflammatory cytokines and chemokines in vitro and in vivo, affecting the development of experimental autoimmune encephalomyelitis. The present study revealed that miR-146a expression was significantly elevated in gastric epithelial cells treated with IL-17A, and miR-146a overexpression could downregulate the expression of inflammatory cytokines, including GRO- $\alpha$ and IL-8. Additionally, miR-146a and IL-17A were upregulated in human gastric mucosa infected with $H$. pylori, suggesting that miR-146a may be an essential regulator in IL-17A-mediated inflammatory responses during the infection of $H$. pylori.

IL-17A can activate the NF- $\kappa$ B signaling pathway $(41,42)$. In the present study, IL-17A activated the NF- $\kappa \mathrm{B}$ signaling during the infection of $H$. pylori. Liu et al (40) revealed that miR-873 directly targeted A20 and promoted the activation of $\mathrm{NF}-\kappa \mathrm{B}$, consequently stimulating the production of inflammatory cytokines and chemokines in astrocytes. As $\mathrm{NF}-\kappa \mathrm{B}$ activation is critical in response to infection, downregulation of this signaling is also essential to prevent excess inflammation, tissue damage and autoimmunity (43). miR-146a is a NF- $\kappa \mathrm{B}$-dependent gene but also can downregulate several signaling mediators involved in inflammatory responses, such as TRAF6 and IRAK1, which are located at the upstream of $\mathrm{NF}-\kappa \mathrm{B}$ and function in a negative feedback loop in regulating of $\mathrm{NF}-\kappa \mathrm{B}$ activity $(44,45)$; this prevents the constitutive activation of $\mathrm{NF}-\kappa \mathrm{B}$ during inflammatory response (46). The results of the present study demonstrated that miR-146a regulated IL-17A-induced proinflammatory cytokines by affecting the expression of IRAK1 and TRAF6 during the infection of H. pylori. IRAK1 and TRAF6 were identified as the direct targets of miR-146a, which downregulated the mRNA levels of IRAK1 and TRAF6 upon stimulation with IL-17A. In addition, silencing of IRAK1 or TRAF6 resulted in suppressed IL-17A-stimulated inflammatory responses in vitro. These findings indicated that miR-146a may be involved in IL-17A-induced pathogenesis of $H$. pylori infection by regulating IRAK1 and TRAF6.

In summary, miR-146a may have suppressed the inflammatory responses upon IL-17A stimulation during infection with $H$. pylori in an NF- $\kappa \mathrm{B}$-dependent manner. These findings provide insight into a potential novel regulatory mechanism in the inflammation associated with $H$. pylori infection. miR-146a may function as a inflammatory suppressor gene in H.pylori-associated gastritis, and may serve as a biomarker or therapeutic target in gastritis therapy.

\section{Acknowledgements}

Not applicable.

\section{Funding}

The present study was supported by National Natural Science Foundation of China (grant no. NSFC, 81501721) and Presidential Foundation of General Hospital of Ji'nan Military Region (grant no. 2017MS06).

\section{Availability of data and materials}

The datasets used and/or analyzed during the current study are available from the corresponding author on reasonable request.

\section{Authors' contributions}

NL conducted the study, collected the data, analyzed the data and wrote the manuscript. JW, WY, KD and FY collected the data and contributed to the introduction. BS and BT performed the experiments and reviewed/edited the manuscript. YZ, TW and BQ designed the study, contributed to the discussion, and edited the manuscript. All authors read and approved the final manuscript.

\section{Ethics approval and consent to participate}

The present study was approved by the Ethics Committee of the Institutional Review Board at The Third Military Medical University, and written informed consent was obtained from all patients.

\section{Patient consent for publication}

Not applicable.

\section{Competing interests}

The authors declare that they have no competing interests.

\section{References}

1. Marshall BJ and Warren JR: Unidentified curved bacilli in the stomach of patients with gastritis and peptic ulceration. Lancet 1: 1311-1315, 1984.

2. Atherton JC and Blaser MJ: Coadaptation of Helicobacter pylori and humans: Ancient history, modern implications. J Clin Invest 119: 2475-2487, 2009.

3. Komiyama Y, Nakae S, Matsuki T, Nambu A, Ishigame H, Kakuta S, Sudo K and Iwakura Y: IL-17 plays an important role in the development of experimental autoimmune encephalomyelitis. J Immunol 177: 566-573, 2006.

4. Simonian PL, Roark CL, Wehrmann F, Lanham AM, Born WK, O'Brien RL and Fontenot AP: IL-17A-expressing T cells are essential for bacterial clearance in a murine model of hypersensitivity pneumonitis. J Immunol 182: 6540-6549, 2009.

5. Troncone E, Marafini I, Pallone F and Monteleone G: Th17 cytokines in inflammatory bowel diseases: Discerning the good from the bad. Int Rev Immunol 32: 526-533, 2013.

6. Nakae S, Nambu A, Sudo K and Iwakura Y: Suppression of immune induction of collagen-induced arthritis in IL-17-deficient mice. J Immunol 171: 6173-6177, 2003.

7. Khmaladze I, Kelkka T, Guerard S, Wing K, Pizzolla A, Saxena A, Lundqvist K, Holmdahl M, Nandakumar KS and Holmdahl R: Mannan induces ROS-regulated, IL-17A-dependent psoriasis arthritis-like disease in mice. Proc Natl Acad Sci USA 111: E3669-E3678, 2014.

8. Cua DJ and Tato CM: Innate IL-17-producing cells: The sentinels of the immune system. Nat Rev Immunol 10: 479-489, 2010.

9. Cheung PF, Wong CK and Lam CW: Molecular mechanisms of cytokine and chemokine release from eosinophils activated by IL-17A, IL-17F, and IL-23: Implication for Th17 lymphocytes-mediated allergic inflammation. J Immunol 180: 5625-5635, 2008.

10. Luzza F, Parrello T, Monteleone G, Sebkova L, Romano M, Zarrilli R, Imeneo $\mathrm{M}$ and Pallone F: Up-regulation of IL-17 is associated with bioactive IL- 8 expression in Helicobacter pylori-infected human gastric mucosa. J Immunol 165: 5332-5337, 2000. 
11. Mizuno T, Ando T, Nobata K, Tsuzuki T, Maeda O, Watanabe O, Minami M, Ina K, Kusugami K, Peek RM and Goto $H$ : Interleukin-17 levels in Helicobacter pylori-infected gastric mucosa and pathologic sequelae of colonization. World J Gastroenterol 11: 6305-6311, 2005.

12. Sebkova L, Pellicanò A, Monteleone G, Grazioli B, Guarnieri G, Imeneo M, Pallone F and Luzza F: Extracellular signal-regulated protein kinase mediates interleukin 17 (IL-17)-induced IL-8 secretion in Helicobacter pylori-infected human gastric epithelial cells. Infect Immun 72: 5019-5026, 2004

13. Du C, Liu C, Kang J, Zhao G, Ye Z, Huang S, Li Z, Wu Z and Pei G: MicroRNA miR-326 regulates TH-17 differentiation and is associated with the pathogenesis of multiple sclerosis. Nat Immunol 10: 1252-1259, 2009.

14. Lu LF, Boldin MP, Chaudhry A, Lin LL, Taganov KD, Hanada T, Yoshimura A, Baltimore D and Rudensky AY: Function of miR-146a in controlling Treg cell-mediated regulation of Th1 responses. Cell 142: 914-929, 2010.

15. Stittrich AB, Haftmann C, Sgouroudis E, Kühl AA, Hegazy AN, Panse I, Riedel R, Flossdorf M, Dong J, Fuhrmann F, et al: The microRNA miR-182 is induced by IL-2 and promotes clonal expansion of activated helper T lymphocytes. Nat Immunol 11: $1057-1062,2010$

16. Chan EK, Ceribelli A and Satoh M: MicroRNA-146a in autoimmunity and innate immune responses. Ann Rheum Dis 72 (Suppl 2): ii90-ii95, 2013

17. Taganov KD, Boldin MP, Chang KJ and Baltimore D: NF-kappaB-dependent induction of microRNA miR-146, an inhibitor targeted to signaling proteins of innate immune responses. Proc Natl Acad Sci USA 103: 12481-12486, 2006.

18. Zhao JL, Rao DS, Boldin MP, Taganov KD, O'Connell RM and Baltimore D: NF-kappaB dysregulation in microRNA-146a-deficient mice drives the development of myeloid malignancies. Proc Natl Acad Sci USA 108: 9184-9189, 2011.

19. Nahid MA, Satoh M and Chan EK: Interleukin 1 $\beta$-responsive MicroRNA-146a is critical for the cytokine-induced tolerance and cross-tolerance to toll-like receptor ligands. J Innate Immun 7: 428-440, 2015

20. Li N, Xu X, Xiao B, Zhu ED, Li BS, Liu Z, Tang B, Zou QM, Liang HP and Mao XH: H. pylori related proinflammatory cytokines contribute to the induction of miR-146a in human gastric epithelial cells. Mol Biol Rep 39: 4655-4661, 2012.

21. Xiao B, Zhu ED, Li N, Lu DS, Li W, Li BS, Zhao YL, Mao XH, Guo G, Yu PW and Zou QM: Increased miR-146a in gastric cancer directly targets SMAD4 and is involved in modulating cell proliferation and apoptosis. Oncol Rep 27: 559-566, 2012.

22. Liu Z, Wang D, Hu Y, Zhou G, Zhu C, Yu Q, Chi Y, Cao Y, Jia C and Zou Q: MicroRNA-146a negatively regulates PTGS2 expression induced by Helicobacter pylori in human gastric epithelial cells. J Gastroenterol 48: 86-92, 2013.

23. Bhaumik D, Scott GK, Schokrpur S, Patil CK, Campisi J and Benz CC: Expression of microRNA-146 suppresses NF-kappaB activity with reduction of metastatic potential in breast cancer cells. Oncogene 27: 5643-5647, 2008

24. Nahid MA, Pauley KM, Satoh M and Chan EK: miR-146a is critical for endotoxin-induced tolerance: IMPLICATION IN INNATE IMMUNITY. J Biol Chem 284: 34590-34599, 2009.

25. Kim DJ, Park KS, Kim JH, Yang SH, Yoon JY, Han BG, Kim HS, Lee SJ, Jang JY, Kim KH, et al: Helicobacter pylori proinflammatory protein up-regulates NF-kappaB as a cell-translocating Ser/Thr kinase. Proc Natl Acad Sci USA 107: 21418-21423, 2010.

26. Hou J, Wang P, Lin L, Liu X, Ma F, An H, Wang Z and Cao X: MicroRNA-146a feedback inhibits RIG-I-dependent Type I IFN production in macrophages by targeting TRAF6, IRAK1, and IRAK2. J Immunol 183: 2150-2158, 2009.

27. Livak KJ and Schmittgen TD: Analysis of relative gene expression data using real-time quantitative PCR and the 2(-Delta Delta C(T)) method. Methods 25: 402-408, 2001

28. Tang B, Li N, Gu J, Zhuang Y, Li Q, Wang HG, Fang Y, Yu B, Zhang JY, Xie QH, et al: Compromised autophagy by MIR30B benefits the intracellular survival of Helicobacter pylori. Autophagy 8: 1045-1057, 2012.

29. Kimang'a A, Revathi G, Kariuki S, Sayed S, Devani S, Vivienne M, Kuester D, Mönkemüller K, Malfertheiner P and Wex T: IL-17A and IL-17F gene expression is strongly induced in the mucosa of $\mathrm{H}$. pylori-infected subjects from Kenya and Germany. Scand J Immunol 72: 522-528, 2010.
30. Liu Z, Xiao B, Tang B, Li B, Li N, Zhu E, Guo G, Gu J, Zhuang Y, Liu X, et al: Up-regulated microRNA-146a negatively modulate Helicobacter pylori-induced inflammatory response in human gastric epithelial cells. Microbes Infect 12: 854-863, 2010.

31. Chen J, Liao MY, Gao XL, Zhong Q, Tang TT, Yu X, Liao YH and Cheng X: IL-17A induces pro-inflammatory cytokines production in macrophages via MAPKinases, NF- $\mathrm{KB}$ and AP-1. Cell Physiol Biochem 32: 1265-1274, 2013.

32. Ernst PB and Gold BD: The disease spectrum of Helicobacter pylori: The immunopathogenesis of gastroduodenal ulcer and gastric cancer. Annu Rev Microbiol 54: 615-640, 2000.

33. Caruso R, Fina D, Paoluzi OA, Del Vecchio Blanco G, Stolfi C, Rizzo A, Caprioli F, Sarra M, Andrei F, Fantini MC, et al: IL-23-mediated regulation of IL-17 production in Helicobacter pylori-infected gastric mucosa. Eur J Immunol 38: 470-478, 2008.

34. Numasaki M, Watanabe M, Suzuki T, Takahashi H, Nakamura A, McAllister F, Hishinuma T, Goto J, Lotze MT, Kolls JK and Sasaki H: IL-17 enhances the net angiogenic activity and in vivo growth of human non-small cell lung cancer in SCID mice through promoting CXCR-2-dependent angiogenesis. J Immunol 175: 6177-6189, 2005.

35. Vykhovanets EV, Maclennan GT, Vykhovanets OV and Gupta S: IL-17 Expression by macrophages is associated with proliferative inflammatory atrophy lesions in prostate cancer patients. Int J Clin Exp Pathol 4: 552-565, 2011.

36. Shiomi S, Toriie A, Imamura S, Konishi H, Mitsufuji S, Iwakura Y, Yamaoka Y, Ota H, Yamamoto T, Imanishi J and Kita M: IL-17 is involved in Helicobacter pylori-induced gastric inflammatory responses in a mouse model. Helicobacter 13: 518-524, 2008.

37. Krebs CF, Kapffer S, Paust HJ, Schmidt T, Bennstein SB, Peters A, Stege G, Brix SR, Meyer-Schwesinger C, Müller RU, et al: MicroRNA-155 drives TH17 immune response and tissue injury in experimental crescentic GN. J Am Soc Nephrol 24: 1955-1965, 2013.

38. He C, Shi Y, Wu R, Sun M, Fang L, Wu W, Liu C, Tang M, Li Z, Wang $\mathrm{P}$, et al: miR-301a promotes intestinal mucosal inflammation through induction of IL-17A and TNF- $\alpha$ in IBD. Gut 65 : 1938-1950, 2016

39. Niimoto T, Nakasa T, Ishikawa M, Okuhara A, Izumi B, Deie M, Suzuki O, Adachi N and Ochi M: MicroRNA-146a expresses in interleukin-17 producing $\mathrm{T}$ cells in rheumatoid arthritis patients. BMC Musculoskelet Disord 11: 209, 2010

40. Liu X, He F, Pang R, Zhao D, Qiu W, Shan K, Zhang J, Lu Y, Li Y and Wang Y: Interleukin-17 (IL-17)-induced microRNA 873 (miR-873) contributes to the pathogenesis of experimental autoimmune encephalomyelitis by targeting A20 ubiquitin-editing enzyme. J Biol Chem 289: 28971-28986, 2014.

41. Doreau A, Belot A, Bastid J, Riche B, Trescol-Biemont MC, Ranchin B, Fabien N, Cochat P, Pouteil-Noble C, Trolliet P, et al: Interleukin 17 acts in synergy with B cell-activating factor to influence B cell biology and the pathophysiology of systemic lupus erythematosus. Nat Immunol 10: 778-785, 2009.

42. Shalom-Barak T, Quach J and Lotz M: Interleukin-17-induced gene expression in articular chondrocytes is associated with activation of mitogen-activated protein kinases and NF-kappaB. J Biol Chem 273: 27467-27473, 1998.

43. Ruland J: Return to homeostasis: Downregulation of NF- $\kappa \mathrm{B}$ responses. Nat Immunol 12: 709-714, 2011.

44. Selvamani SP, Mishra R and Singh SK: Chikungunya virus exploits miR-146a to regulate NF- $\kappa \mathrm{B}$ pathway in human synovial fibroblasts. PLoS One 9: e103624, 2014.

45. He X, Zheng Y, Liu S, Shi S, Liu Y, He Y, Zhang C and Zhou X: MiR-146a protects small intestine against ischemia/reperfusion injury by down-regulating TLR4/TRAF6/NF- $\mathrm{BB}$ pathway. J Cell Physiol 233: 2476-2488, 2018.

46. Sundaravinayagam D, Kim HR, Wu T, Kim HH, Lee HS, Jun S, Cha JH, Kee Y, You HJ and Lee JH: miR146a-mediated targeting of FANCM during inflammation compromises genome integrity. Oncotarget 7: 45976-45994, 2016. 